\title{
Analysis of the influence of selected factors on natural greenhouse ventilation
}

\author{
Stawomir Grabarczyk ${ }^{1, *}$ \\ ${ }^{1}$ Institute of Civil Engineering, Faculty of Civil Engineering, Mechanics and Petrochemistry, Warsaw \\ University of Technology, Łukasiewicza 17, 09-400 Płock, Poland
}

\begin{abstract}
In greenhouses, in order to maintain proper indoor air temperature; during the period of high values of solar radiation intensity, shading treatments using thermal screens and ventilation are applied. The research was carried out in a mono-span greenhouse in order to determine the effectiveness of natural ventilation. The object of analysis is a greenhouse with a thermal screen installed inside. The tests were carried out during the summer days. The effect of the research was to determine the ventilation air flow through the vents of the greenhouse on the basis of measurements and calculation analyzes. The dependence of the air flow on the windward and leeward side was determined from the wind speed and the temperature difference between the indoor and outdoor air. On the basis of calculations made from observation during shading of the cultivated area and with open ventilators, the coefficients of air exchange per unit floor area of the greenhouse were determined. It was established that at a wind speed exceeding $0.8 \mathrm{~m} / \mathrm{s}$, the air exchange rate in the tested greenhouse exceeds the value recommended by the American Society of Agricultural Engineers of $0.04 \mathrm{~m}^{3} /\left(\mathrm{sm}^{2}\right)$.
\end{abstract}

\section{Introduction}

Greenhouse ventilation in the summer is one of the main factors affecting the formation of the microclimate. Natural ventilation is the simplest and cheapest solution in these types of facilities. In the conditions of variable external climate in Poland, in greenhouses, mainly due to costs, thermal screens are used to reduce heat losses in the period of low temperatures and to allow shading of the greenhouse's floor area during high solar radiation. A supplementation for the use of thermal screens is the use of something additional on the sidewalls by tightly fixing e.g. an air bubble foil. At the same time, it prevents the use of side vents of greenhouses in the summer.

The effect of shading screens on greenhouse ventilation was investigated by Lee and Short [1]. The effect of using thermal screens can be to reduce solar radiation and temperature in the greenhouse, but also to reduce ventilation and increase the temperature inside the greenhouse. According to research, the thermal screen has no effect on the ventilation efficiency if the size of the gaps between the screen sections is greater than the

* Corresponding author: slawomir.grabarczyk@pw.edu.pl 
size of the ventilation openings. The ventilation efficiency tests carried out by Kittas et al. [2] show that roof ventilators are more effective than side vents.

Experimental research on the effectiveness of ventilation in greenhouses is expensive, therefore the development of Computational Fluid Dynamics techniques allowed for the simulation of shaping the greenhouse microclimate with analysis and visualization of air flow. A review of experimental research in this field as well as CFD simulation experiments is presented by Bournet and Boulard [3]. In the comparison of experimental studies, there are no results regarding the greenhouse presented in the analyzes. It was decided to use the experience of other authors and perform appropriate calculations to determine the effectiveness of natural greenhouse ventilation with roof ventilators during high solar radiation values. The general assessment of the efficiency of ventilation of the tested greenhouse was determined on the basis of the requirements defined by the American Society of Agricultural Engineers [4], which recommends ventilation in the summer at the level of $0.04 \mathrm{~m}^{3} /\left(\mathrm{s} \mathrm{m}^{2}\right)$.

The aim of the analyzes was to determine the effectiveness of natural ventilation in the roof ventilators in the period of high solar radiation values, based on the conducted tests in a greenhouse with a thermal screen.

\section{Theoretical basis}

The flow of ventilation air between the interior of the greenhouse and the external environment through the ventilation openings depends on the pressure difference between the air inside and outside the greenhouse. The pressure difference between these centers is caused by the difference in air density due to the difference in temperature, and can also be caused by wind.

The model of air exchange in the greenhouse was theoretically developed by Bot and presented in a publication [5] and developed based on experimental research done by Jong [6]. Field research in this area was conducted among others by Bailey [7], Boulard [8], Papadakis [9] and Teitel [10-11]. The models of air exchange due to the new possibilities of using CFD techniques have been partially verified, hence it is possible to use specific relationships to determine the effectiveness of ventilation in other greenhouses. Boulard and Baille [12] analyzed the air flow through the ventilators with flaps in the roof or in the sidewall of a greenhouse and proposed the following equation (1):

$$
Q=\left(\frac{A}{2}\right) C_{d} \sqrt{\frac{2 g\left(\frac{h}{4}\right)\left(T_{i}-T_{e}\right)}{\bar{T}}+C_{w} w^{2}}
$$

where:

$Q$ - ventilation rate, $\mathrm{m}^{3} / \mathrm{s} ; A$ - sum of the areas of the ventilation opening, $\mathrm{m}^{2} ; C_{d}$ - the discharge coefficient of the ventilation opening; $g$ - the acceleration of gravity, $\mathrm{m} / \mathrm{s}^{2}$; $h$ - the vertical dimension of the ventilation opening (2), $\mathrm{m} ; T_{i}$ - internal air temperature, ${ }^{\circ} \mathrm{C} ; T_{e}$ - external air temperature, ${ }^{\circ} \mathrm{C} ; \overline{\mathrm{T}}$ - the mean absolute temperature, $\mathrm{K} ; C_{w}$ - the global wind pressure coefficient; $w$ - the wind speed, $\mathrm{m} / \mathrm{s}$.

$$
h=H_{0}[\sin (\psi)-\sin (\psi-\alpha)]
$$

where:

$H_{o}$ - height of the opening, $\mathrm{m} ; \psi$ - roof slope angle, ${ }^{\circ} ; \alpha$ - opening angle, ${ }^{\circ}$. 


\section{Materials and method}

The subject of the research was a mono-span greenhouse located in Skierniewice in a complex of twenty greenhouses. Analyzes of the efficiency of natural greenhouse ventilation with open ventilators were made for the facility located closest to the meteorological station operating for the purpose of controlling the greenhouse microclimate. The station measuring the external climate parameters is located at a distance of $22 \mathrm{~m}$ from the longitudinal axis of the greenhouse. The location of the sensors on the mast is at the same height on which the roof vents of the greenhouse are located.

The tests were carried out in a mono-span greenhouse, with $4 \mathrm{~mm}$ thick external glass partition covering. A thick air bubble foil was attached to the surface of the sidewalls. Inside the greenhouse, parallel to the side walls and the roof slope, a thermal screen ULS 16 has been installed with shading and energy saving properties, functioning depending on external climatic conditions. The volume of the greenhouse with screen, limited by its surface and the surface of the other partitions, constitutes $88,4 \%$ of the greenhouse volume without additional covers. This screen is a fabric made of polyester and aluminum strips. Natural ventilation in the summer period is carried out by opening roof ventilators with dimensions of $1.47 \mathrm{~m} \mathrm{x} 30.78 \mathrm{~m}$, two vents are located on the leeward side and two on the windward side of the greenhouse. The greenhouse substrate is adapted for growing potted plants. Basic information about the greenhouse is presented in the Table 1.

Table 1. Characteristics of the greenhouse.

\begin{tabular}{|c|c|c|}
\hline \multirow{2}{*}{$\begin{array}{c}\text { mono-span } \\
\text { greenhouse }\end{array}$} & length & $62.5 \mathrm{~m}$ \\
\cline { 2 - 3 } & width & $20 \mathrm{~m}$ \\
\cline { 2 - 3 } & ridge height & $7.3 \mathrm{~m}$ \\
\cline { 2 - 3 } & gutter height & $2.2 \mathrm{~m}$ \\
\cline { 2 - 3 } & roof slope angle & $27^{\circ}$ \\
\hline \multirow{2}{*}{ vent } & roof ventilators with flap & $4 \times 1.47 \mathrm{~m} \times 30.78 \mathrm{~m}$ \\
\hline covers & $\begin{array}{c}\text { energy saving } \\
\text { shading }\end{array}$ & $60 \%$ \\
\hline ULS 16 & & $65 \%$ \\
\hline
\end{tabular}

Research on the effectiveness of ventilation in the period of high solar radiation values was carried out between 11-17 of July 2007. Measurements of the parameters necessary to perform the analyzes were recorded within an interval of 10 minutes. The general characteristics of the basic parameters of the external climate and greenhouse microclimate during measurements are presented in Table 2.

Table 2. Statistic of climatic conditions during measurements (11-17 of July 2007).

\begin{tabular}{|c|c|c|c|c|c|c|c|c|}
\hline \multicolumn{2}{|c|}{ Parameters } & 11.07 & 12.07 & 13.07 & 14.07 & 15.07 & 16.07 & 17.07 \\
\hline \multirow{2}{*}{$T_{i}\left[{ }^{\mathbf{0}} \mathbf{C}\right]$} & mean & 24.2 & 23.3 & 23.4 & 30.9 & 39.9 & 41.8 & 42.2 \\
\cline { 2 - 9 } & st. dev. & 2.1 & 2.1 & 1.8 & 4.0 & 5.3 & 4.6 & 4.8 \\
\hline \multirow{2}{*}{$\boldsymbol{T}_{\boldsymbol{e}}\left[^{\mathbf{0}} \mathbf{C}\right]$} & mean & 18.8 & 17.9 & 18.8 & 25.3 & 32.7 & 35.4 & 36.1 \\
\cline { 2 - 9 } & st. dev. & 1.9 & 1.2 & 1.3 & 2.6 & 1.9 & 2.0 & 2.3 \\
\hline \multirow{2}{*}{$\boldsymbol{w}[\mathbf{m} / \mathbf{s}]$} & mean & 0.7 & 1.9 & 2.1 & 1.6 & 1.6 & 1.9 & 1.6 \\
\cline { 2 - 9 } & st. dev. & 0.5 & 1.1 & 1.2 & 1.0 & 1.2 & 1.2 & 1.1 \\
\hline \multirow{2}{*}{$\boldsymbol{I}_{\boldsymbol{d}}\left[\mathbf{W} / \mathbf{m}^{\mathbf{2}}\right]$} & mean & 179.1 & 151.2 & 143.2 & 236.8 & 322.9 & 343.2 & 340 \\
\cline { 2 - 9 } & st. dev. & 131.9 & 96.7 & 98.6 & 185.7 & 209.4 & 206 & 205 \\
\hline
\end{tabular}


The occurrence of direct radiation during the measurement period is shown in Fig. 1.

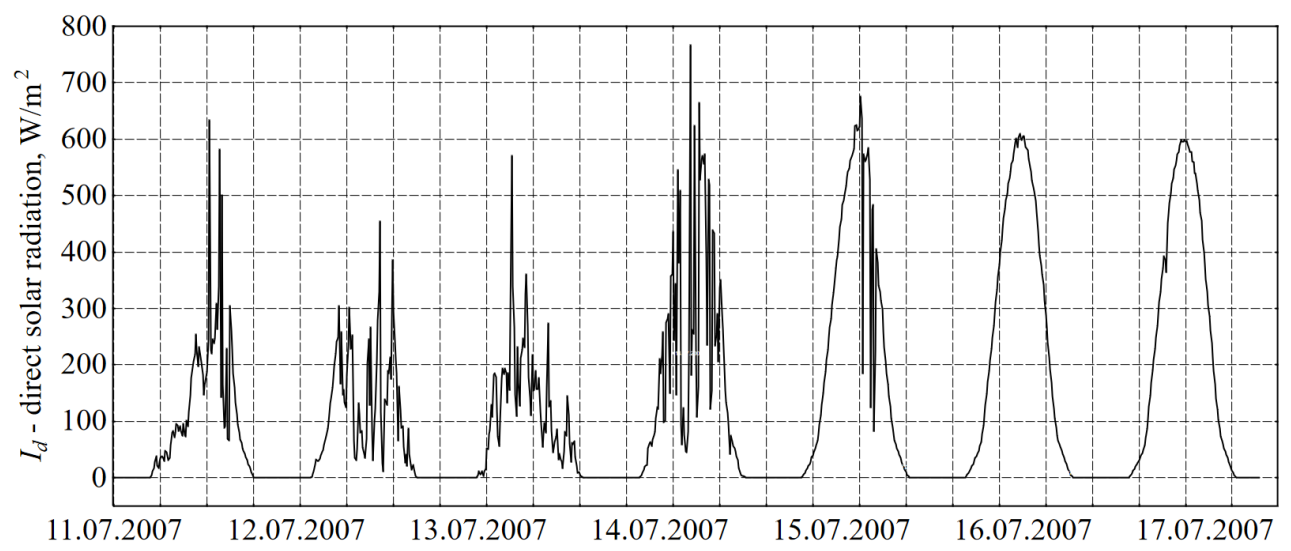

Fig. 1. Direct solar radiation observed during the seven selected days (11-17 July 2007).

\section{Result and discussion}

Based on the dependence (1) and measurements in the greenhouse, the ventilation air flow through the roof ventilators was determined. The regression equations determining the dependence of the ventilation air flow on the wind speed were established. Coefficients of correlation and determination indicate the main driving force which is the wind speed. The dependence of air exchange on the wind speed in the period of high values of solar radiation intensity is shown in Fig. 2.

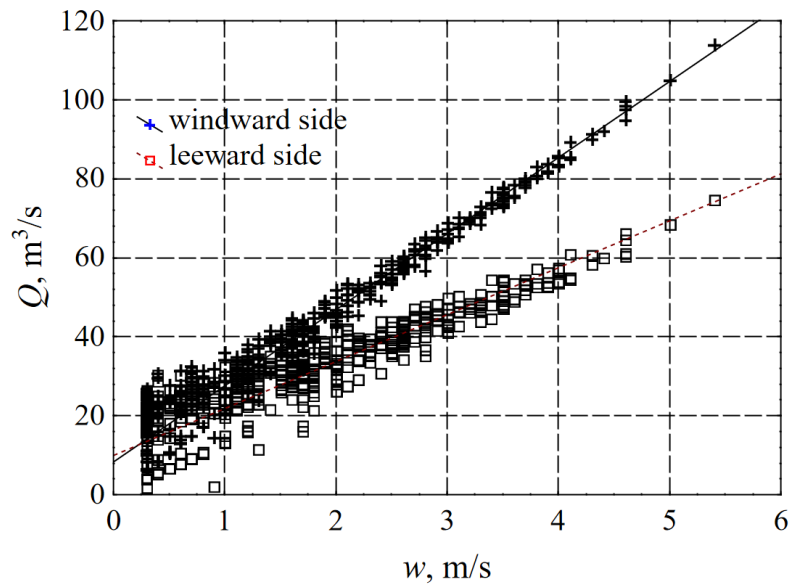

Fig. 2. Ventilation rates for roof ventilators with flap covers.

In windless weather, the ventilation air flow through the vents on both sides of the greenhouse are the same. The increase in wind speed is the greater contribution of the windward side to the total airflow exchanged in the greenhouse. At a wind speed of $4 \mathrm{~m} / \mathrm{s}$, the share of the windward side in the total airflow exchanged in the greenhouse is $60 \%$ (Fig. 3). 


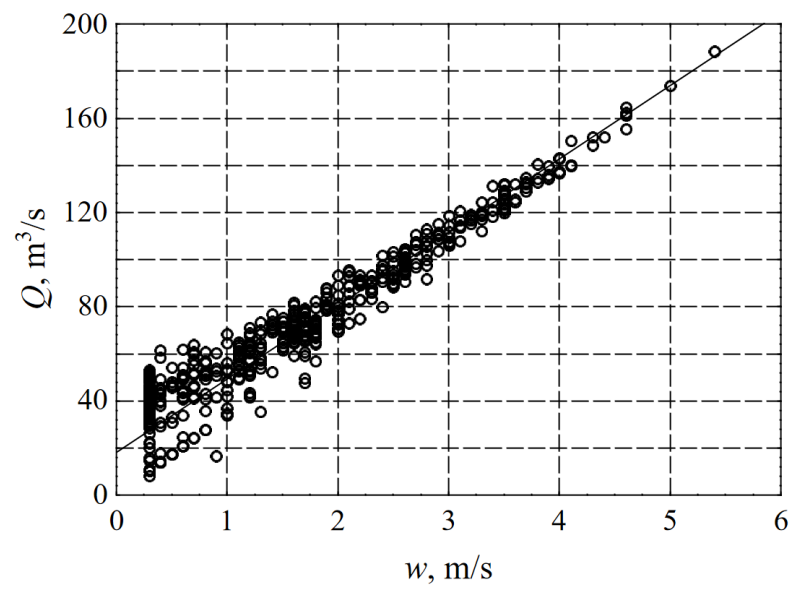

Fig. 3. Ventilation rates for roof ventilators with flap covers.

Values of $C_{d}$ and $C_{w}$ coefficients were adopted according to literature data [13], which for roof ventilators are respectively: $C_{d}=0.649$ and $C_{w}=0.1$ for windward vent and $C_{d}=0.037$ for leeward. The basis for the classification of a given observation describing the role of a wind functioning on the leeward and windward side was determined on the basis of indications of the wind direction from the measurement system monitoring the external climate parameters. The calculations do not include changes in the $C_{d}$ coefficient from the vent opening angle. In the case of sunny days with low wind speeds, there is not enough data available for analysis in this respect. The vents open to the maximum position and the number of observations for angles between 0 and 60 degrees is very small.

The linear regression equations of the air flow dependence on the wind speed in the investigated greenhouse are presented in Table 3 . The increase of the wind speed by $1 \mathrm{~m} / \mathrm{s}$ causes the increase of the air flow exchanged in the greenhouse by about $31 \mathrm{~m}^{3} / \mathrm{s}(5)$.

Table 3. Linear regression equations of ventilation rate.

\begin{tabular}{|c|c|c|c|c|c|c|}
\hline $\begin{array}{c}\text { Ventilator } \\
\text { type }\end{array}$ & $\begin{array}{c}\text { numb. } \\
\text { of obs. }\end{array}$ & Regression equation & $\mathbf{R}$ & $\mathbf{R}^{\mathbf{2}}$ & std. error & equation \\
\hline $\begin{array}{c}\text { Flap roof } \\
\text { windward }\end{array}$ & 628 & $Q=8.351+19.225 \cdot w$ & 0.976 & 0.952 & 0.319 & $(3)$ \\
\hline $\begin{array}{c}\text { Flap roof } \\
\text { leeward }\end{array}$ & 628 & $Q=9.934+11.870 \cdot w$ & 0.915 & 0.837 & 0.386 & $(4)$ \\
\hline $\begin{array}{c}\text { Flap roof } \\
\text { (windward } \\
\text { and }\end{array}$ & 628 & $Q=18.284+31.126 \cdot w$ & 0.956 & 0.914 & 0.701 & $(5)$ \\
\cline { 2 - 7 } leeward) & 502 & $Q_{A}=0.0227+0.022 \cdot w$ & 0.975 & 0.951 & 0.0005 & $(7)$ \\
\hline
\end{tabular}

The dependence of the size of the ventilation air flow on the second causative factor, which is the temperature difference (6), is shown in Fig. 4. In this case, correlation and determination coefficients are lower than in the case of analogous equations defined for wind speed. 


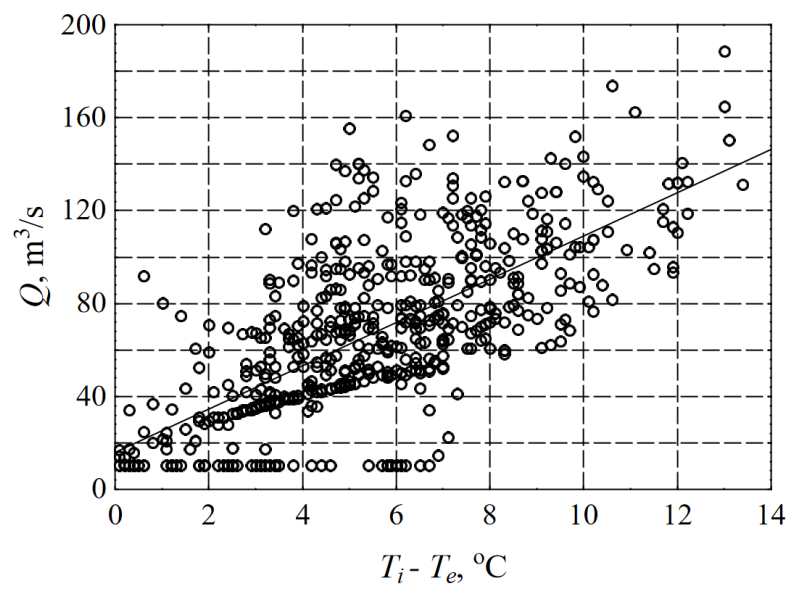

Fig. 4. Ventilation rates for roof ventilators with flap covers.

According to Papadakis [9], wind is the main driving force of natural ventilation in a greenhouse above the speed of $1,8 \mathrm{~m} / \mathrm{s}$, while at lower wind speeds the force causing the ventilation process is the force of thermal buoyancy. In the tested object with large sets of 4 roof ventilators with dimensions of $1,47 \mathrm{mx} 30.78 \mathrm{~m}$, located two on the leeward side and two on the windward side, the influence of thermal buoyancy may be even smaller. For this purpose, it is required to carry out tests in a wider range of solar radiation and different opening angles of the vents.

The ventilation air flow determined on the basis of the tests was converted to the greenhouse floor area and was used to establish the air exchange rate. The values of this air exchange rate for observations during the measurement period are shown as dependence on wind speed (7). A graphic illustration of this dependence is shown in Fig. 5.

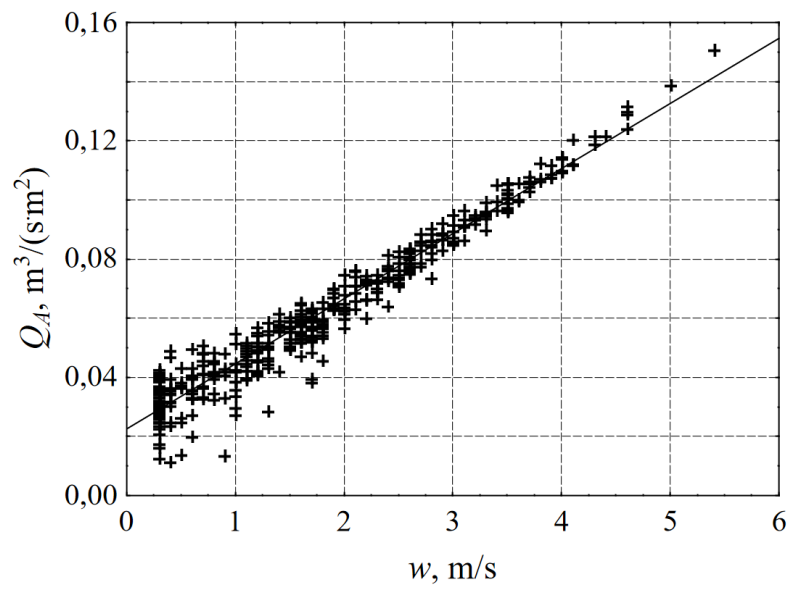

Fig. 5. Ventilation rates per greenhouse floor area.

Comparison of the values obtained for the range of sunny measuring days with the value determined according to ASAE [4] at the level of $0.04 \mathrm{~m}^{3} /\left(\mathrm{sm}^{2}\right)$ allows to state that on the basis of the relationship (7) at a wind speed of $0.8 \mathrm{~m} / \mathrm{s}$, this limit is exceeded. In sunny and windless weather there is a risk of not meeting the condition for proper shaping of the microclimate in the plant growing zone in the greenhouse. It is important to 
realize that this is a general indicator that can be used to assess natural ventilation in a greenhouse.

The analysis of the occurrence of temporary values of the ventilation coefficient per unit area is presented in the histogram (Fig. 6).

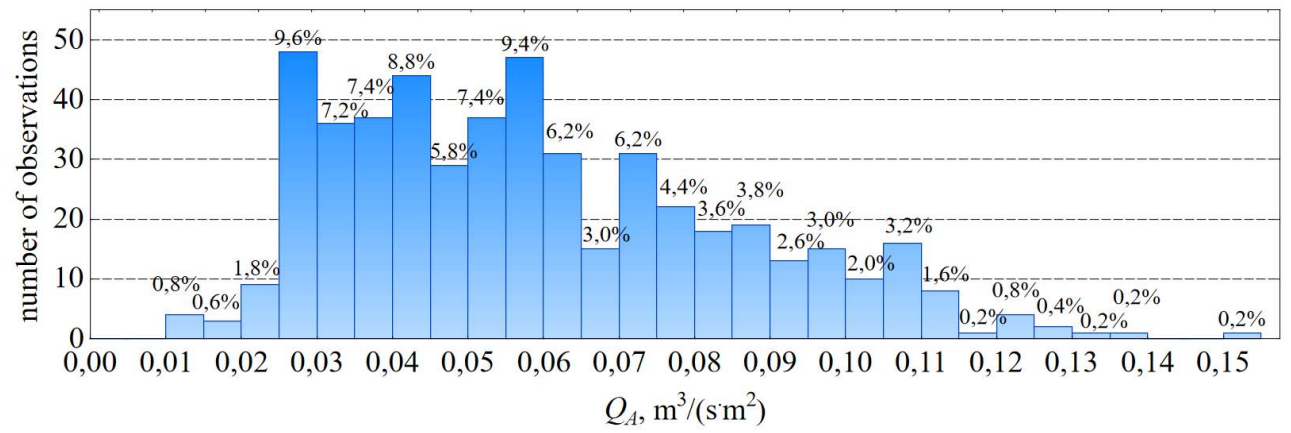

Fig. 6. Histogram of the ventilation coefficient per unit area.

The presented distribution of values of the ventilation coefficient shows that in the examined period, for $27 \%$ of observations, the criterion of effective ventilation at the level of $0.04 \mathrm{~m}^{3} /\left(\mathrm{s} \mathrm{m}^{2}\right)$ was not met. Statistically significant values of the ventilation coefficient are greater than $0.025 \mathrm{~m}^{3} /\left(\mathrm{s} \mathrm{m}^{2}\right)$, which, given the variable wind speed observations, suggests that there is no significant risk of disturbances in air exchange and proper shaping of the microclimate in the greenhouse.

\section{Conclusions}

As a result of the analysis, the efficiency of ventilation in a mono-span greenhouse with roof ventilators and a thermal screen installed inside was determined. Analyzes carried out for sunny days and measurements made in a mono-span greenhouse allowed for the determination of the flow of ventilation air through the vents of the windward and leeward side of the greenhouse. The dependence of the ventilation air flow on the wind speed and the difference in air temperature allowed for the conclusion that the main driving force of natural ventilation in the tested greenhouse is the wind speed. It was found that at wind speeds above $0.8 \mathrm{~m} / \mathrm{s}$, the condition regarding effective ventilation of the greenhouse's growing area as defined in the ASAE [4] requirements is met.

A more complete assessment of the effectiveness of ventilation in the greenhouse can be made using, for example, CFD (Computational Fluid Dynamics) or Particle Image Velocimetry techniques. The first ones require verification of experimental data and are extremely time-consuming, while PIV techniques are expensive to implement. Therefore, the general air exchange rate and measurements of external climate parameters and microclimate made in the greenhouse were used to assess the effectiveness of natural ventilation.

Improvement in the functioning of natural ventilation in a greenhouse can be achieved by opening side ventilators, however, it is necessary to take into account the need to improve the tightness of the air bubble foil assembly before each heating season. In addition, air flow from side ventilators can locally increase air velocity in the plant growing zone at significant instantaneous wind speeds.

Roof ventilators account for approx. $8 \%$ of the greenhouse roof area, while the thermal screen is $70 \%$ closed during shading of the cultivated area. Large spacing between the sections of the shade screen installed in the greenhouse do not limit the effect of thermal 
buoyancy force, according to the conclusions from Lee and Short [1]. It is advisable to check the efficiency of greenhouse ventilation, e.g. by closing $80 \%$ of the shade screen. It is possible that the temperature increase in the plant growing zone would be smaller through simultaneously meeting the condition of limiting the air flow in the greenhouse by the thermal screen installed inside.

\section{References}

1. I.B. Lee, T.H. Short, 91 st Annual International Meeting of ASAE, 987014 (1998)

2. C. Kittas, B. Draoui, T. Boulard, Agric. For. Meteo., 77, 95 (1995)

3. P.E. Bournet, T. Boulard, Comp. Electr. Agric., 74, 195 (2010)

4. ASAE Standards, EP406.4: Heating, Ventilating and Cooling Greenhouses (2003)

5. G.P.A. Bot, Greenhouse climate: From physical processes to a dynamic model (Agricultural University, Wageningen, 1983)

6. T. de Jong, Natural ventilation of large multi-span greenhouses (Agricultural University, Wageningen, 1990)

7. B.J. Bailey, A.P. Robertson, A.G. Lockwood, Acta Hort., 633, 197 (2004)

8. T. Boulard, J.F. Meneses, M. Merimer, G. Papadakis, Agric. For. Meteo., 79, 61 (1996)

9. G. Papadakis, M. Merimer, J.F. Meneses, T. Boulard, J. Agr. Eng. Res., 63, 219 (1996)

10. M. Teitel, O. Liran, J. Tanny, M. Barak, Biosyst. Eng. 101 (1), 111 (2008)

11. M. Teitel, G. Ziskind, O. Liran, V. Dubovsky, R. Letan, Biosyst. Eng. 101, 351 (2008)

12. T. Boulard, A. Baille, J. Agr. Eng. Res., 61, 37 (1995)

13. J. Pérez Parra, E. Baeza, J.I. Montero, B.J. Bailey, Biosyst. Eng. 87 (3) 355 (2004) 